\title{
Innovative Design of a Sea Wave Energy Harnesser
}

\author{
D. Ionescu ${ }^{1}$, B.S. Ngwenya ${ }^{2}$
}

\author{
${ }^{1}$ Department of Mechanical Engineering Technology \\ Faculty of Engineering and Built Environment, University of Johannesburg \\ Doornfontain Campus - Johannesburg (South Africa) \\ Phone/Fax number:+27 11 5596509, e-mail: dorinai@uj.ac.za
}

\author{
${ }^{2}$ Department of Mechanical Engineering \\ Faculty of Engineering, Mangosuthu University of Technology, Umlazi-Durban (South Africa) \\ Phone/Fax, e-mail+27 31819 9294, e-mail boniso@ mut.ac.za . \\ M-Tech student with the University of Johannesburg, \\ Department of Mechanical Engineering Technology.
}

\begin{abstract}
.
The aim of this research is to design and develop a simple, light and cost-effective wave energy conversion device. The mass to power ratio is of importance to achieve high working efficiency. In addition proper control concept is proposed for various sea wave conditions to manage the system optimally.

The potential wave resource in South Africa is enormous as there are over $2000 \mathrm{~km}$ of coastline with an annual wave height average of $2-3 \mathrm{~m}$. One of the most efficient wave energy extractor is the hinged wave energy converter (HIWEC) whereby the wave force is applied to a responsive mechanism able to resist the working force of the waves. The hinged mechanism used in this project is of the power take-off (PTO) type. The PTO captures the wave energy and then between the wave's time intervals transfers it to be converted and stored. Control of the response of the HIWEC can be achieved through active tuning of the PTO. As wave energy is intermittent, the supplied electrical power will show strong variations unless an energy storage system is available. The energy storage system consists of several series connected gas accumulators, placed in the hydraulic circuit to produce a smoothing effect.
\end{abstract}

\section{Key words}

Green energy, Wave energy harvesting, Grid connection.

\section{Introduction}

The wave energy harnessing is a relatively new technology, as only in 2008 the world first wave plant to produce $2.25 \mathrm{MW}$ of power was commissioned in Portugal [1]. The harnessing of energy from ocean waves requires the waves to apply force to some form of responsive mechanism able to resist the working force of the waves, and have a fulcrum against which that mechanism can react. The hinged mechanism provides means by which energy is transferred during the time interval between the waves and a hydraulic system, generally known as the power take-off (PTO). Control of the response of a HIWEC can be achieved through active control of the PTO. Extracting maximum possible time average power from waves, while reducing the risk of device damage, is a combination of good fundamental engineering design of the devices and effective control of their operation. This research addresses the above two problems by considering the system mechanical structure and schemes designed to achieve optimal control. Methods employed to achieve maximum power output are inevitably non-causal and require prediction of the shape of the incident waves.

\section{Design of the Sea Wave energy harnesser}

The efficiency of the wave harnesser project is measured both in terms of the power capture efficiency and mass to power ratio which influences the overall system cost. A systems design approach was used to develop the conceptual design of the Hinged Wave Energy Converter (HIWEC). Figure 1 shows the general assembly of the HIWEC designed and built at Mangosuthu University of Technology.

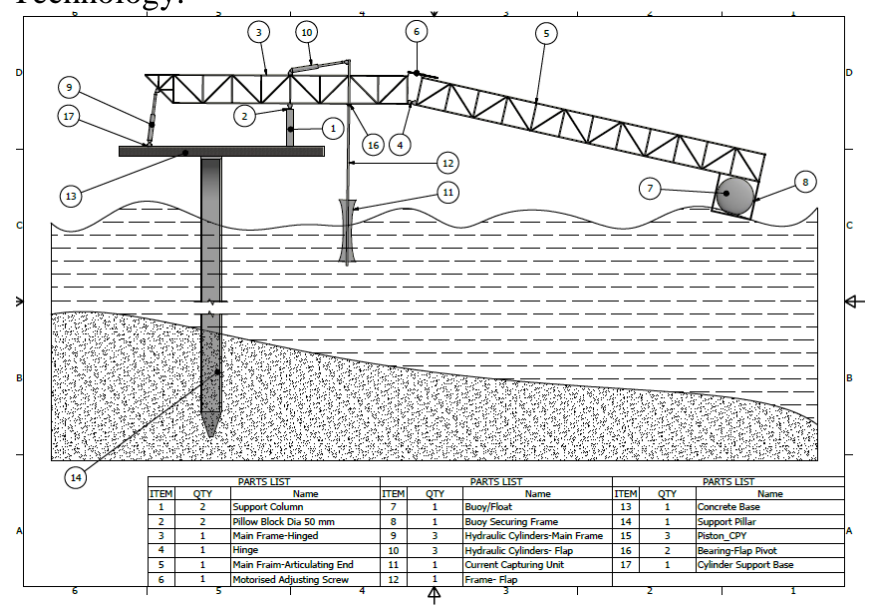

Fig. 1 HIWEC - General assembly

The concept of extracting energy from sea waves is very old and since the first patent was filed by Girard in 1799 there have been many attempts to siphon wave energy for electrical production [2]. These efforts have resulted in pre and commercial WEC projects such as various buoy concepts, oscillating water column (OWC) plants, the Pelamis WEC, overtopping WEC like the wave Dragon, point absorber approaches used in the wave star etc.[3]. 
To date wave energy has not been considered in South Africa as part of the renewable energy mix and no assessments were undertaken to shed light on its prospects. The worldwide potential of the wave power is estimated to be approximately $2 \mathrm{TW}$ [4]. The wave properties of the coastal regions of South Africa are very favourable to the installation of wave power converting devices.

\section{A. Design parameters}

Wave surfaces are three-dimensional and multifaceted entities, characterised by main direction, wave height, and energy periods.

1) Linear effects For a given wind profile quasilaminar theory is fairly successful in predicting growth rates and waves induced profiles. It ignores, however a possible change of wind profile while ocean waves are evolving. The momentum transfer from wind to waves may be so large that the associated wave induced stress becomes a substantial fraction of the turbulent stress [5].

2) Nonlinear effects As the velocity profile over sea waves is controlled by both turbulent and waveinduced momentum flux [5], deviations from the profile of turbulent airflow over a flat plate are to be expected. In addition the energy transfer from air to the waves may be affected by the sea state so that a strong coupling between the turbulent boundary layer and the surface waves is expected.

\section{B. General governing equations}

A buoy vessel that heaves in water will produce waves. A big vessel and a small vessel may produce equal waves provided the smaller body oscillates with larger amplitude. This principle was utilised for the purpose of wave energy conversion devices. The response of the wave device to incident wave must be designed such that it oscillates close to the wave amplitude. Generally a good wave absorber makes a good wave maker. In the design of the HIWEC the governing equation of a single body with single degree of freedom oscillation in heave is taken into consideration. The hydrodynamic diffraction model is a well-known representation of a buoy in heave. As the waves are propagating in an infinite water depth with small motion the following equation is then valid:

$$
\begin{aligned}
& (M+a(\omega)) \frac{d^{2} x(t)}{d t^{2}}+\mathrm{B}(\omega) \frac{d x(t)}{d t}+k x(t)= \\
& =F_{E}(t)-F_{L}(t)
\end{aligned}
$$

Where:

$M=$ mass of the buoy module $[\mathrm{kg}]$

$a(\omega)=$ added mass from the body of water $[\mathrm{kg}]$

$\mathrm{x}=$ displacement $[\mathrm{m}]$

$B(\omega)=$ frequency dependant damping $[\mathrm{Ns} / \mathrm{m}]$

$k=$ mechanism stiffness $[\mathrm{N} / \mathrm{m}]$

$F_{E}=$ the excitation force caused by the wave action [N]

$F_{L}=$ Power take off force (PTO) [N]
The frequency excitation on vertical direction can be defined as a sinus wave function of time:

$$
\chi=\mathrm{A} \sin \omega \mathrm{t}
$$

Where:

$\mathrm{A}=$ oscillation amplitude $[\mathrm{m}]$

$\omega=$ circular frequency of the oscillation generating a simple harmonic motion [rad/s]

The wave power is defined as:

$$
\mathrm{P}_{\text {wave }}=\frac{\rho g^{2} T_{e} H_{S}^{2}}{64 \pi},[\mathrm{W} / \mathrm{m}]
$$

Where:

$\rho=$ density of sea water $\left[\mathrm{kg} / \mathrm{m}^{3}\right]$

$\mathrm{g}=$ acceleration due to gravity $\left[\mathrm{m} . \mathrm{s}^{-2}\right]$

$\mathrm{T}_{\mathrm{e}}=$ wave period [seconds]

$\mathrm{H}_{\mathrm{s}}=$ significant wave height $[\mathrm{m}]$

The dynamics and interactions between low-frequency swells and the atmosphere play a critical role in understanding wave motion. The basic equation describing these interactions is the Boltzmann integral proposed by Hasselmann [6] and a couple of years later by Zakharov [7] who derived it in a form known as the kinetic equation. Hasselmann [6] developed the theoretical framework for nonlinear four wave interactions for homogeneous seas with a constant depth. He formulated an integral expression for the computation of these interactions, which is known as the Boltzmann integral for surface gravity waves. Hasselmann [6] found that a set of four waves, called a quadruplet, could exchange energy when several resonance conditions are satisfied.

The displacement of the buoy gravity centre in the frame of calm free water surface is represented by a coordinate $\mathrm{z}[\mathrm{m}]$ on the vertical axis. The floating buoy motion is then derived from Newton's second law.

$$
m_{m} z=F_{e}+F_{r}+F_{b}+F_{v}+F_{f}+F_{u},[N]
$$

Where:

$\mathrm{F}_{\mathrm{e}}=$ excitation force $[\mathrm{N}]$;

$\mathrm{F}_{\mathrm{r}}=$ radiated force acting on the buoy vessel $[\mathrm{N}]$;

$\mathrm{F}_{\mathrm{b}=}$ hydrostatic buoyancy $[\mathrm{N}]$;

$\mathrm{F}_{\mathrm{v}}$ and $\mathrm{F}_{\mathrm{f}}$ are the viscous and friction effects $[\mathrm{N}]$;

$\mathrm{F}_{\mathrm{u}}=$ force supported by the control device assisting the operation of the oscillating body [N].

The excitation force $\mathrm{F}_{\mathrm{e}}$ can be defined as:

$$
\mathrm{F}_{\mathrm{e}}=\operatorname{k\rho g} \pi \mathrm{a}^{2} \chi
$$

Where: $\mathrm{k}$ is non-dimension excitation force coefficient defined as $\mathrm{k}=2 \pi / \lambda$, and $\lambda$ is the wave length; $\rho=$ density of sea water $\left[\mathrm{kg} / \mathrm{m}^{3}\right]$;

$a=$ added mass from the body of water $[\mathrm{kg}]$

$\chi=$ frequency excitation on vertical direction. $[\mathrm{Hz}]$

\section{Spectral dissipation due to wave breaking}

The theory of breaking dissipation is crucial when identifying the potential site for installing a wave farm. Wave breaking theory started with the work of LonguetHiggins [8]. Donelan and Yuan [9] and Young and Babanin [10], provide more recent work in wave 
dynamics that accommodates most recent advances in the field. Of the models which consider the waves prior to the breaking, the first analytical type developed was a probability model suggested by Longuet-Higgins [8] and further developed by Yuan et al.[11] and Hua and Yuan [12]. All these studies used the Gaussian distribution of surface elevations to predict the appearance of wave heights exceeding the height of the Stokes' limiting wave or its limiting acceleration of $0.5 \mathrm{~g}$ at the crest, (where $\mathrm{g}$ is the gravitational acceleration).

1) Bottom dissipation The dissipation in the wave energy equation is not very well known. The wave energy equation explicitly contains a term for white capping in the deep water [12]. As waves approach shallower waters, they start to feel the bottom. There is a non-negligible wave induced oscillatory current at the sea-bed and the spectrum adopts a new selfsimilar shape in which the enhanced dissipation becomes evident [13]. The wind input, nonlinear transfer and white-capping are terms that take different forms in depth limited conditions and there is evidence of interaction between waves with the sea bed. Several sea beds related dissipative processes are known but none of them is very accurate.

2) Waves and currents Research has been conducted in investigating the effects of the interaction between waves and currents on the sea bed. These interactions are not completely understood and there is debate about whether the interaction is weak or strong. In the concept of strong interaction both the wave and current bottom stresses are enhanced due to non-linear interactions. The sea bed stress under combined waves and currents is larger than the sum of the waves and currents only. In spite of the importance of these effects on tidal current modelling, there seems to be little field validation of the wave current theories. There is evidence that waves affect the sea bed friction experienced by the mean flow.

\section{South African general conditions for wave energy harvesting}

Wave energy resource is characterised in terms of sea state parameters. The bulk of the annual wave energy is provided by waves with significant wave heights of 1.5$4.0 \mathrm{~m}$, energy periods of 6-16.5 s, and mean deep-water direction NW-NW. Figure 2 shows the wave energy profile around South Africa (whether bureau information)

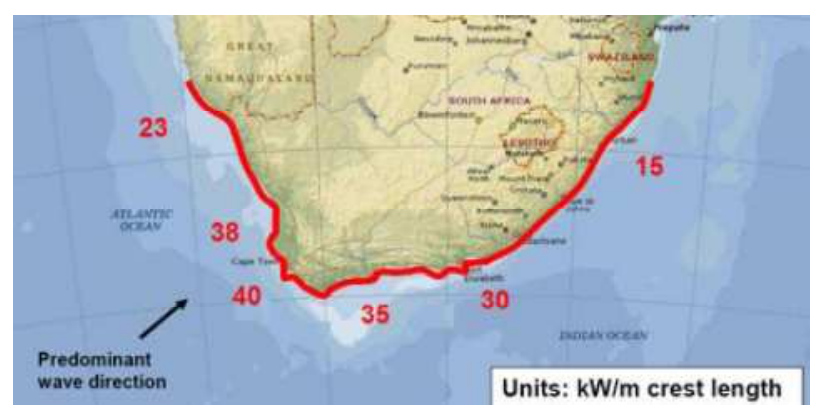

Fig. 2 - Wave energy profile around South Africa
Due to high energy density of flowing sea water, good predictability and minimal environmental impact, harnessing sea water flow energy with buoy is one of the best options among renewable energy technologies. The tides create horizontal movements of water in the oceans and they usually occurs near sea shore in bays and estuaries along the coast and change in very regular pattern which means they can be predicted for future dates. Both the rise and fall of the waves and the flood and ebb of the reversing current can be harnessed to produce electrical energy. Data referring to the waves on South African shores were collected in March 2012 and are illustrated in figures 3, 4, 5, 6 and 7 .

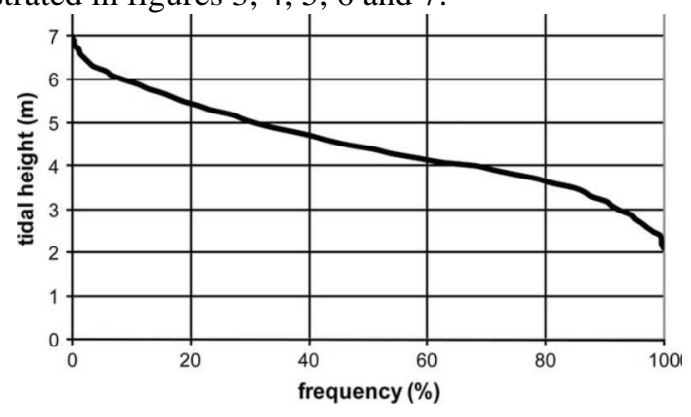

Fig. 3 - The waves height frequency prediction

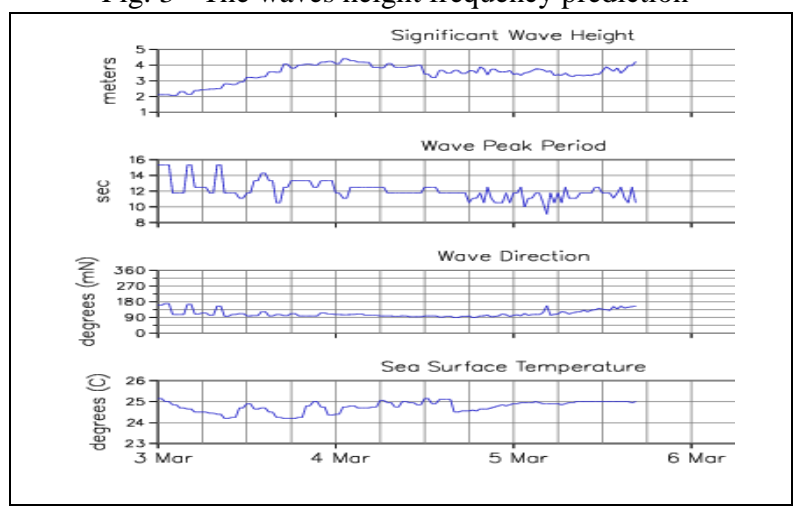

Fig. 4 - Sea state parameters

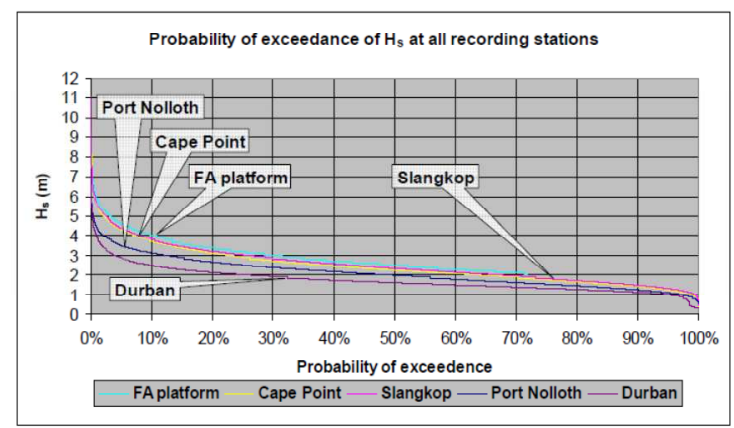

Fig. 5 - Probability of exceeding $\mathrm{H}_{\mathrm{s}}$ for South African recording stations

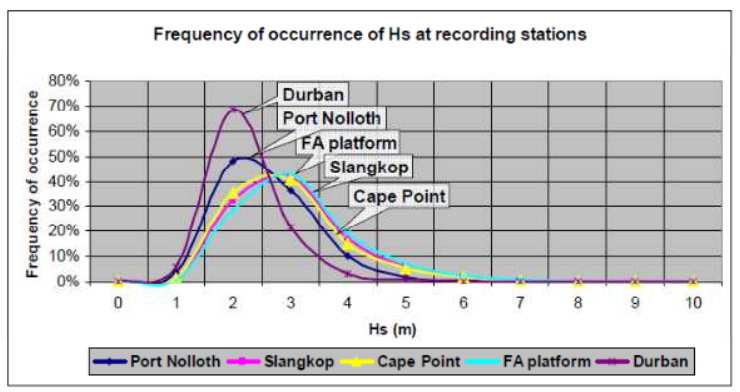

Fig. 6 - Frequency occurrences of $\mathrm{H}_{\mathrm{s}}$ 


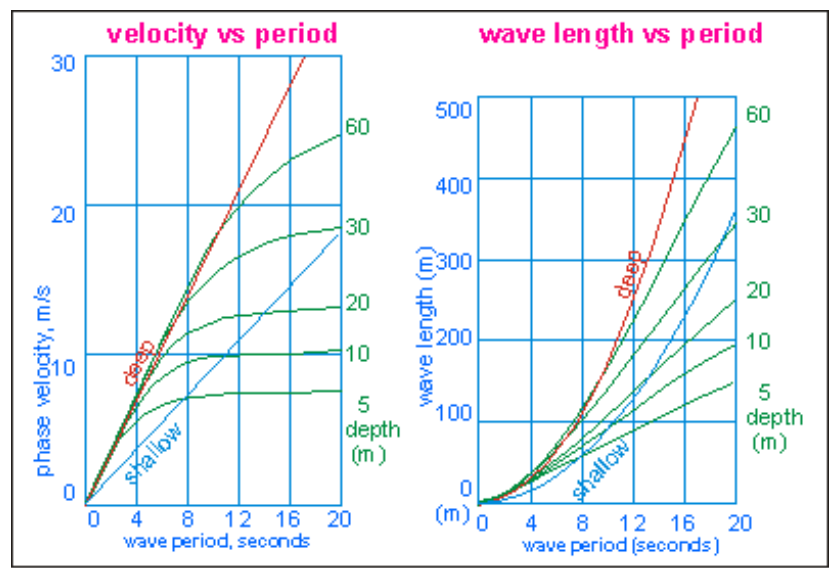

Several variants of the Hinged Wave Energy Converter (HIWEC) were built and tested in laboratory conditions at Mangosuth University of Technology. The HIWEC can be deployed and arranged in multi-unit arrays to extract energy from the ocean in basically the same way as a wind farm operates. As opposed to the rigid, expensive, and environmentally-aggressive construction of tidal barrages, the modularity and scalability of wave energy devices are becoming more attractive features. Figure 8 shows the last variant of the HIWEC built at Mangoshutu University of Technology, with the main parts identified.

Fig. 7 - Typical wave velocity, wave length and period in deep and shallow waters

\section{Sea Wave Energy Harnesser Prototype}

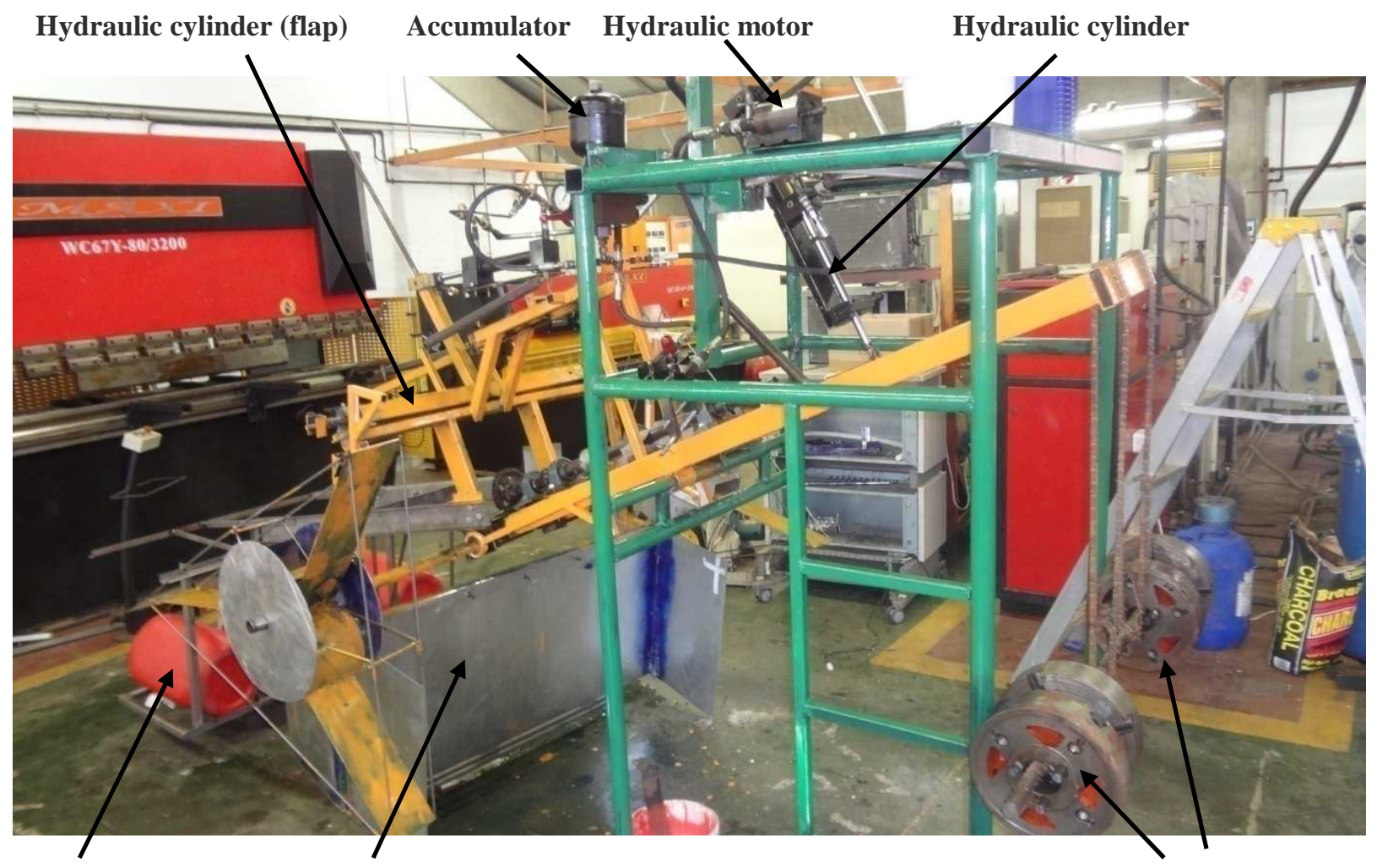

Buoy vessel

Flap mechanism

Balance masses

Fig. 8 - HIWEC full-scale prototype

\section{A HIWEC control strategy}

Devices for control and power take-off comprise controllable valves, hydraulic rams and an articulating structure, buoy volume control as well as electronic software and hardware components. The very large variation of the energy input from a wave group over a short time period and the energy storage capability, is incorporated into the system. The mechanical configuration and mass of the HIWEC can be altered during operation, rendering it suitable for active tuning. The floating-buoy converter is adjusted to optimise the power take off (PTO) and also to protect the system from extreme weather conditions, such as storms, tsunamis etc. Table 1 shows the characteristics of the 12 sea states indicating wave climate, damping values and pressure difference. The sea state parameters are changed approximately every 10 minutes in order to calculate the mean values of the time period and significant wave height. The data collected are then supplied to the position based feedback system. The HIWEC is optimally tuned for conditions of low energy wave climates and in more energetic wave conditions sea water will be pumped into the buoy acting as additional mass. A control system that constantly monitors the pressure 
difference between the accumulators, wave height, and period is integrated to the HIWEC to adjust the PTO damping values and motorised articulated frame. The design was done for a pressure variation ranging from minimum value of 5 bar to maximum value of 160 bar.

Table 1 - Characteristics of the 12 sea states

\begin{tabular}{|l|l|l|l|l|}
\hline $\mathrm{n}$ & $\mathrm{H}_{\mathrm{s}}[\mathrm{m}]$ & $\mathrm{T}_{\mathrm{e}}[\mathrm{s}]$ & $\begin{array}{l}\text { Damping value based } \\
\text { on \% valve opening }\end{array}$ & $\Delta P($ bar $)$ \\
\hline 1 & 1.08 & 5.47 & 0 & 160 \\
\hline 2 & 1.14 & 6.60 & 66.25 & 54 \\
\hline 3 & 1.23 & 7.76 & 20 & 120 \\
\hline 4 & 1.87 & 6.63 & 9.34 & 145 \\
\hline 5 & 1.96 & 7.21 & 66.67 & 50 \\
\hline 6 & 2.06 & 9.75 & 50 & 80 \\
\hline 7 & 2.15 & 7.23 & 62.66 & 56 \\
\hline 8 & 3.07 & 8.03 & 37.50 & 100 \\
\hline 9 & 3.20 & 9.94 & 14 & 129 \\
\hline 10 & 3.20 & 11.72 & 63.75 & 58 \\
\hline 11 & 3.29 & 9.85 & 14.38 & 137 \\
\hline 12 & 4.76 & 12.03 & 53.33 & 70 \\
\hline
\end{tabular}

Considering the values in table 1, the full-scale prototype shown in figure 8 was built to have a range of natural oscillation periods between 6 and $16 \mathrm{~s}$, respectively. The significant wave heights in South African waters, would allow it to be actively tuned to realistic wave periods, ranging from low energetic wave conditions to what could be expected during a storm or heavy swell conditions has been built and tested.

\section{B Motion Analysis of the HIWEC mechanism}

The cylinder force is constantly controlled by adjusting the flow control valve based on the differential pressure across the HP and LP accumulators. The tuning of the damping values using optimal damping coefficients is computed for each hourly spectrum. Figure 9 shows schematically the functioning of the HIWEC mechanism.
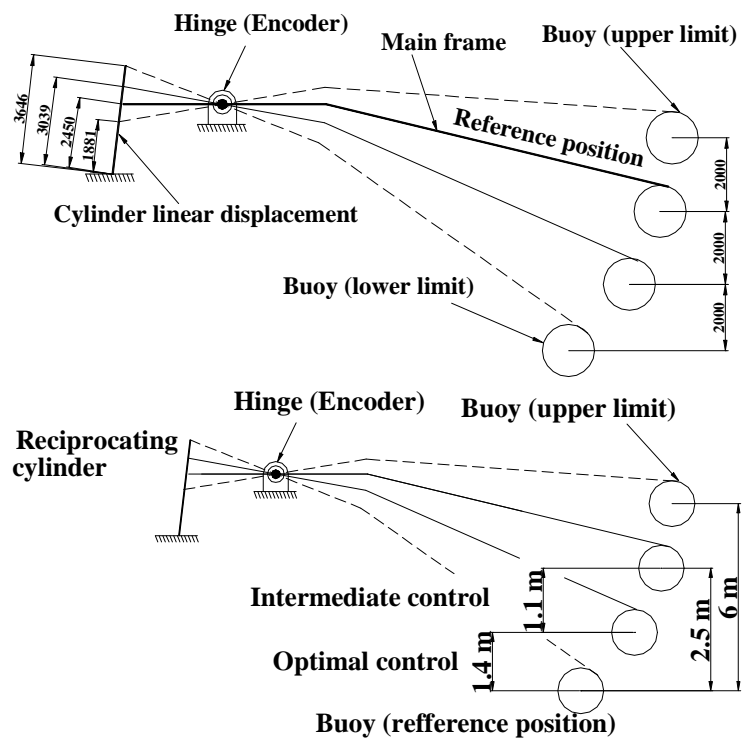

Fig. 9 - movement of the HIWEC mechanism (Drawing not to scale)

\section{Conclusions}

In the process of developing a new concept, it is important to learn from previous successes and failures.

- Using a simple mechanical structure oscillating on hinged the wave force can be amplified to maximise the power output.

- For monitoring the movement at the pivot point an encoder, tachometer and torque sensor capable of recording heaving, incident wave force and frequency parameters were mounted.

- By adjusting the damping coefficient the movement parameters can be controlled.

- An extensive literature review revealed that very few on site ocean trials were conducted. The reason for this lack of experimental data probably is the great difficulty in working with experiments in an ocean environment. Many of the projects have reported on sensor failures, unforeseen events, and other general problems in making measurements at sea.

- The most common site measurements were found to be: wave height (using different technologies), device motion and mooring forces. The motion measurements methods were different for the majority of the projects, and many varying methods were used, such as accelerometers, wire sensors, GPS systems, optical systems and echo sounders.

\section{References}

[1] A. Al-Habaibeh a,*, D. Sub, J. McCague c, A. Knight 2010, "An innovative approach for energy generation from waves", Journal of Energy conversion and Management, pp 1665

[2] Simon Lindroth, Mats Leijoh, "Offshore wave power measurement" 2011, Renewable and Sustainable energy review journal

[2] Snyder, R.L., 1974. "A field study of wave-induced pressure fluctuation above surface gravity waves", Journal of Marine Research 32, 497-531.

[3] Drew B,Plummer AR, Sahinkaya MN. A review of wave energy converter technology. Journal of Power and Energy, Proceeding of the Institute of Mechanical Engineering, Part A 2009;223:887-902

[4] Soren R.K Nielsen, Qiang Zhou, Morten M Kramer, Biswajit Basu, Zili Zhang "Optimal control of nonlinear wave energy point converter", 2013, journal of ocean engineering.

[5] Snyder, R.L., 1974. "A field study of wave-induced pressure fluctuation above surface gravity waves", Journal of Marine Research 32, 497-531.

[6] Hasselmann, K., 1962. "On the non-linear energy transfer in a gravity-wave spectrum; Part 1, General theory", Journal of Fluid Mechanics12, 481-500.

[7] Zakharov, V.E., 2002. "Theoretical interpretation of fetchlimited wind-driven sea observations", the 7th International Workshop on Wave Hindcasting and 
Forecasting, Banff, Alberta, October 21-25, 2002, pp. 286-295.

[8] Longuet-Higgins, M.S., 1969a, "On wave breaking and the equilibrium spectrum of wind-generated waves", Proceedings of the Royal Society London A 310, 151159.

[9] Donelan, M.A., Yuan, Y., "Wave dissipation by surface processes", 1994.

[10] Babanin, A.V., Young, I.R., 2005, "Two-phase behaviour of the spectral dissipation of wind waves". In: Proceedings of the Fifth International Symposium WAVES 2005, 3-7 July, 2005, Madrid, Spain.
[11] Yuan, Y., Tung, C.C., Huang, N.E., 1986. Statistical characteristics of breaking waves. In: Phillips, O.M., Hasselmann, K. (Eds.), Wave Dynamics and Radio Probing of the Ocean Surface. Plenum Press, New York, pp. 265-272.

[12] Hua, F., Yuan, Y., 1992. Theoretical study of breaking wave spectrum and its application. In: Banner, M.L., Grimshaw, R.H.J. (Eds.),Breaking Waves, IUTAM Symposium, Sydney, Australia, 1991. Springer, Berlin, Heidelberg, pp. 277-282.

[13] Monbaliu, J., Padilla-Herna'́ndez, R., Hargreaves, J.C., Albiach, J.C.C., Luo, W., Sclavo, M., Günther, H., 2000. The spectral wave model WAM, adapted for applications with high spatial resolution. Coastal Engineering 41-62. 